\title{
Relation between intragastric bile acid concentration and mucosal abnormality in the stomach after vagotomy and gastroenterostomy for duodenal ulcer
}

\author{
PCH WATT, ${ }^{*}$ JM SLOAN, ${ }^{*}$ TL KENNEDY $\dagger$ \\ From the Departments of ${ }^{*}$ Pathology and $†$ Surgery, Royal Victoria Hospital, Belfast
}

SUMMARY A high incidence of possible premalignant conditions of the gastric mucosa has been reported in the postoperative stomach and it has been suggested that bile plays a role in their pathogenesis.

Fifty eight patients who had had a vagotomy and gastrojejunostomy betwen 1957 and 1967 underwent endoscopy and biopsy. Subsequently, samples of fasting and postprandial gastric juice were taken from all patients for analysis of total bile acid. The patients were divided into three histological groups: group 1 (24 patients) had gastritis or mucosal atrophy but no more than mild dysplasia; group 2 (23 patients) had intestinal metaplasia in one or more biopsies; group 3 (11 patients) had moderate or severe dysplasia in one or more biopsies. Group 2 and group 3 patients had higher fasting intragastric bile acid concentrations than group 1 ( $p<0.01$ in both cases). There was no difference between fasting bile acid concentrations in groups 2 and 3 . In the postprandial phase groups 2 and 3 also had higher peak intragastric concentrations than group 1 ( $\mathrm{p}<0.01$ in both cases). Again, there was no significant difference between groups 2 and 3 .

It is concluded that there is a relation between mucosal abnormality in the postoperative stomach and intragastric bile acid concentration. The possible aetiological link between bile acid and these mucosal abnormalities is discussed.

There is now considerable evidence that surgery for benign peptic ulceration is associated in the long term with a high incidence of gastric carcinoma. ${ }^{1-3}$ This has prompted a number of endoscopic and biopsy studies of groups of patients who have had gastric surgery. ${ }^{4-8}$ These studies have shown a high incidence of mucosal abnormality and a number of unsuspected gastric cancers have been found. ${ }^{4}$

The pathogenesis of premalignant and malignant conditions in the stomach after operation is controversial. Several studies have suggested that the bacteria which proliferate in the hypochlorhydric stomach are capable of reducing dietary nitrate to nitrite and of further reducing nitrite to $\mathrm{N}$-nitroso compounds, which are known to be carcinogenic, at least in experimental animals. ${ }^{90}$ Other studies have suggested that bacteria break down the bile acids, which reflux into the stomach leading to metabolites which could be carcinogenic in the long term. ${ }^{11}$

The object of this study was to investigate the relation between intragastric bile acid concentration

Accepted for publication 16 January 1984 and histological abnormality in a group of patients who had undergone gastric surgery.

\section{Patients and methods}

In a previous study 82 patients who had undergone vagotomy and gastrojejunostomy were subject to endoscopy and biopsy. The methods used for endoscopy, biopsy, and histological assessment have previously been reported. ${ }^{6}$ Briefly, at the time of endoscopy seven biopsies were taken from each patient, and each biopsy was individually assessed for gastritis, atrophy, intestinal metaplasia, and dysplasia. Of these 82 patients, 58 returned for gastric juice sampling and they form the basis of this report. All had undergone vagotomy and gastrojejunostomy in the Royal Victoria Hospital, Belfast, between 1957 and 1967 . There were 47 men and 11 women, with a mean age of 60.3 years (range $43-77$ years). Most of the patients were asymptomatic, but five complained of diarrhoea, three of oesophagitis, three of dumping symptoms, and one had symptoms suggestive of bile reflux. 
For the purposes of this study the 58 patients were divided into three histological groups. Group 1 had no intestinal metaplasia and no more than mild dysplasia in any biopsy. All these patients had various degrees of gastritis and mucosal atrophy. There were 24 patients in this group (17 men, seven women) and their mean age was $60 \cdot 1$ years. Group 2 patients had intestinal metaplasia in one or more biopsies, in addition to gastritis and mucosal atrophy. There were 23 patients in this group ( 21 men, two women) and their mean age was 61.3 years. Group 3 patients had moderate (10 patients) or severe (one patient) dysplasia in at least one biopsy. These patients also had various degrees of gastritis and mucosal atrophy and, in addition, seven also had intestinal metaplasia in one or more biopsy. There were 11 patients in group 3 (nine men, two women) and their mean age was 58.8 years. Analysis of variance showed no significant difference in the age distribution between the three groups.

Before gastric juice sampling all the patients fasted overnight. A size 14 Salem sump nasogastric tube was passed and the position checked radiologically. After 30-45 min the stomach was completely aspirated and the aspirate used only for analysis of nitrite and $\mathrm{N}$-nitroso compounds, the results of which are to be reported. Gastric juice was then collected over a 30 min period. A meal containing $18 \mathrm{~g}$ of corn oil and $12 \mathrm{~g}$ of glucose made up to 100 $\mathrm{ml}$ with warm water was then given via the nasogastric tube. Aliquots $(10 \mathrm{ml})$ of gastric juice were then aspirated 20,40, and $60 \mathrm{~min}$ after the meal. The $\mathrm{pHs}$ of the preprandial samples were measured using a Corning model $113 \mathrm{pH}$ meter.

\section{BILE ACID ANALYSIS}

Analysis of total bile acid was carried out on all fasting and postprandial samples using reagent mixtures as described for the commercial kit produced by Nyegaard (Sterognost $3 \alpha$ Pho), which is based on the technique used by Fausa and Skalhegg. " This technique involves the oxidation of bile acids by the enzyme $3 \alpha$-hydroxysteroid dehydrogenase with concomitant reduction of NAD to $\mathrm{NADH}_{2}$. The $\mathrm{NADH}_{2}$ is produced mole for mole from bile acids and can readily by measured using a spectrophotometer (Pye Unicam SP8-100) set to measure extinction at $340 \mathrm{~mm}$. All assays were carried out on $100 \mu \mathrm{l}$ samples of gastric juice at room temperature and $\mathrm{pH} 9 \cdot 5$. Readings were taken after a reaction time of $20-40 \mathrm{~min}$ as recommended by Fausa and Skalhegg.

The assay was linear (coefficient of correlation $=$ 0.999) for cholic acid standard solutions up to a concentration of $1000 \mu \mathrm{mol} / \mathrm{l}$. The assay was also linear for bile acids in gastric juice over a similar range (coefficient of correlation $=0.992$ ).

To assess reproducibility 12 aliquots of a minimally bile stained sample of gastric juice were assayed. The mean concentration was $108.03 \mu \mathrm{mol} / \mathrm{l}$ and the coefficient of variation was $3.7 \%$. The same gastric juice was then spiked with cholic acid in order to raise the bile acid concentration by 200 $\mu \mathrm{mol} / \mathrm{l}$. Twelve aliquots were assayed, giving a mean value of $284.8 \mu \mathrm{mol} / \mathrm{l}$ (coefficient of variation = $2.02 \%$ ). The recovery of cholic acid was $90.4 \%$.

The effect of $\mathrm{pH}$ on recovery of bile acids was minimal. The addition of the corn oil to gastric juice, however, reduced recovery by about $13 \%$.

Table Bile acid concentrations in preprandial and postprandial samples

\begin{tabular}{|c|c|c|}
\hline & \multicolumn{2}{|c|}{ Bile acid concentration ( $\mu \mathrm{mol} / \mathrm{l})^{*}$} \\
\hline & Preprandial & Postprandial \\
\hline \multirow[t]{2}{*}{$\begin{array}{l}\text { Group 1 } \\
(\mathrm{n}=24) \\
\text { Group 2 } \\
(\mathrm{n}=23) \\
\text { Group 3 } \\
(\mathrm{n}=11) \\
\text { All patients } \\
(\mathrm{n}=58)\end{array}$} & $\begin{array}{l}197 \cdot 7 \\
(0-11985) \\
1448 \\
(0-26835) \\
8040 \\
(1690-25911)\end{array}$ & 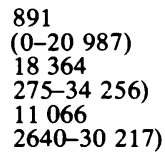 \\
\hline & $(0-26835)$ & $(0-34256)$ \\
\hline
\end{tabular}

${ }^{*}$ Values given as median (range)

\section{Results}

\section{PREPRANDIAL SAMPLES}

The ranges of bile acid concentration for preprandial samples are shown in the Table. Values for all groups are plotted in Fig. 1. Significantly higher preprandial bile acid concentrations were found in group 2 compared with group $1(p=0.01)$ and in group 3 compared with group 1 (Mann-Whitney $U$ test; $p=0 \cdot 01$ ). No significant difference was found between groups 2 and 3 .

The $\mathrm{pH}$ values of the preprandial samples in all 58 patients showed a positive correlation with bile acid concentration (Spearman's correlation coefficient $0.79 ; p<0.01)$.

\section{POSTPRANDIAL SAMPLES}

For the purposes of this study, the peak postprandial concentration was used for comparison between groups (Table). The bile acid concentrations for all groups are plotted in Fig. 2. The bile acid concentrations in group 2 and group 3 were both higher than in group 1 (Mann-Whitney $U$ test; $p=0.01$ in both cases). No significant difference was found between groups 2 and 3. 


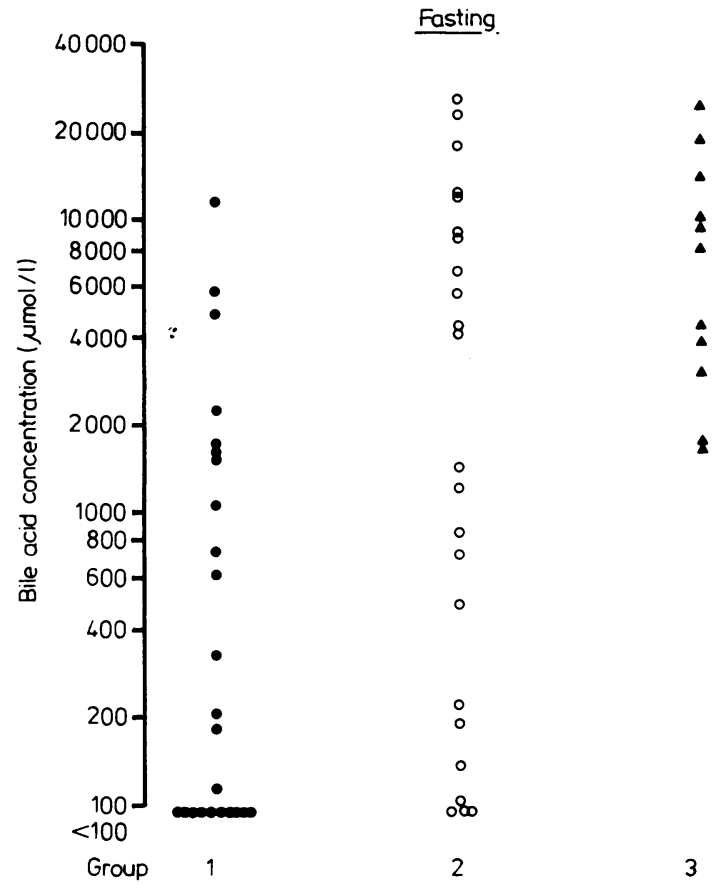

Fig. 1 Fasting gastric juice bile acid concentrations in histological groups of patients who have undergone vagotomy and gastrojejunostomy.

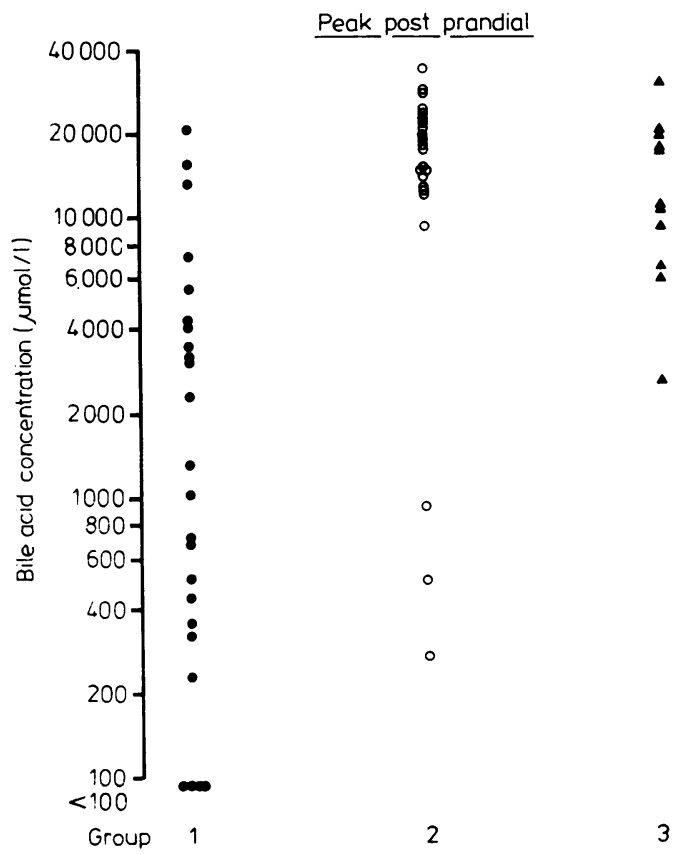

Fig. 2 Peak postprandial gastric juice bile acid concentrations in histological groups of patients who have undergone vagotomy and gastrojejunostomy.

\section{Discussion}

Studies which have followed up over prolonged periods groups of patients who have had gastric surgery have given contradictory results as to whether these patients have a higher than normal incidence of gastric cancer. McClean Ross et al ${ }^{12}$ found no increased incidence of gastric cancer whereas Krause' found an observed to expected ratio of $2 \cdot 2$ for gastric cancer. Schrumpf $e t$ al $^{4}$ found four cases of infiltrating carcinoma in 108 gastrectomy patients at endoscopy, which is more than they would have expected in the normal population. Stalsberg and Taksdal ${ }^{2}$ have shown an increased frequency of previous gastric surgery at necropsy in patients with gastric cancer. These studies concerned either exclusively or mainly gastrectomy patients. Since gastrectomy patients lack the gastric antrum which is that part most likely to undergo malignant change, it might be expected that they would have a lower incidence of gastric cancer than the normal population. The fact that the incidence is at least equal to, if not more than, normal suggests that a carcinogenic process is in progress in the gastric stumps.

The nature of this carcinogenic process is controversial. Reed et $\mathrm{al}^{10}$ found a positive correlation between $\mathrm{pH}$ and $\mathrm{N}$-nitroso compounds in gastric juice. Since these have been shown to be carcinogenic at least in experimental animals, ${ }^{13}$ this group has suggested that they might be responsible for the high incidence of gastric cancer in hypochlorhydric states such as pernicious anaemia and after gastric surgery. Other studies have found no correlation between gastric juice $\mathrm{pH}$ and total $\mathrm{N}$-nitroso compound concentration. ${ }^{14}$ Work from our own laboratories on $\mathrm{N}$-nitroso compounds has found no convincing role for them in the pathogenesis of premalignant mucosal change in patients who have undergone vagotomy and gastrojejunostomy included in the current study.

The uncertainty regarding $\mathrm{N}$-nitroso compounds and the fact that bile acids have been suspected of having a major role in the pathogenesis of colonic cancer ${ }^{15}$ and in cancer following gastric surgery" stimulated this study on the relation between gastric juice bile acid concentration and gastric mucosal histology. The histological groups were chosen because of the strong suspicion that both intestinal metaplasia $^{15}$ and appreciable degrees of dysplasia are premalignant conditions. ${ }^{16}$ Mild dysplasia was included in group 1 as its importance has been questioned ${ }^{17}$ and since in a previous study no significant difference was found in its incidence in vagotomy and gastrojejunostomy and control patients. ${ }^{\circ}$

In this study, considerable effort was made to dis- 
tinguish dysplasia from epithelial regenerative change $^{16}$ using the criteria of Whitehead. ${ }^{18}$ When epithelial regenerative change was diagnosed it was recorded and graded into two grades. Since identification of the lesion is subjective, the reproducibility of this grading was poor and therefore no correlation was attempted between intragastric bile acid and epithelial regenerative change. In a previous repport we showed that our grading of dysplasia and its distinction from epithelial regenerative change was reproducible. ${ }^{6}$ Since epithelial regenerative change was found to some extent in virtually all these postoperative patients, it was considered inappropriate to analyse the differences in intragastric bile acid concentration between those who did and those who did not have the lesion. Mosimann ${ }^{19}$ has used the term foveolar hyperplasia, defined as "elongation and tortuosity of the gastric pits making them appear more frequently than normal in transverse sections." These authors found this change in all their patients who had had gastric surgery. ${ }^{20} \mathrm{We}$ found, however, that foveolar hyperplasia was difficult to assess in a reproducible way.

Owing to the difficulties in quantifying duodenogastric reflux, ${ }^{21}$ gastric bile acid concentration was used in the current study. We considered that concentration of bile acids was a more important factor in determining mucosal damage than the total quantity refluxing into the stomach as the latter does not take into account the dilutional effect of gastric juice. Hoare et $a^{22}$ have shown that this type of technique for the collection of gastric bile acid is reproducible. The relation between bile acid concentration in gastric juice and histological abnormality is in agreement with the work of Ritchie, ${ }^{23}$ who studied early postoperative patients. Thomas et $a^{24}$ found a relation between gastric mucosal dysplasia and bile reflux as measured by H I D A scan and our studies support their findings. Our findings also support the view of Domellof," who suggested that bile metabolites may be important in the pathogenesis of carcinoma following gastric surgery. Domellof $e t a^{25}$ subsequently showed the presence of unconjugated and secondary bile acids in the gastric juice of postgastrectomy patients. Deoxycholic acid has been shown to promote carcinogenesis in the mouse rectum. ${ }^{26}$ Hill $e t a^{27}$ have shown that bacteria can metabolise bile acids into possible carcinogenic substances, and several studies have shown that bacteria proliferate in the hypochlorhydric stomach. ${ }^{1028}$ There would therefore appear to be a theoretical basis for suggesting an aetiological role for bile acting as a carcinogen in hypochlorhydric stomachs and our data would tend to support this theoretical view.

In the fasting state patients in groups 1 and 2 appeared to have a wide range of bile acid concen- trations, whereas group 3 patients all tended to have high intragastric bile acid concentrations, although there were only 11 patients in this group. Group 2 patients tended to have a greater response to the test meal. We are unable to explain this adequately, although a speculative suggestion is that the anatomical arrangement of the stoma in these patients might predispose them to a sudden increase of gastric bile acid concentration after contraction of the gallbladder.

We have found an association between intragastric bile acid concentration and histological abnormality. This does not rule out the possibility that some other substance is responsible for the mucosal change and that bile is acting merely as a marker for that substance. In particular, lysolecithin ${ }^{29}$ has been suggested as a cause of gastric mucosal damage. Our data apply only to total bile acids, although we are currently investigating the association between mucosal damage and the various bile acid fractions. We have previously shown a relation between gastric mucosal abnormality and high $\mathrm{pH} .{ }^{30}$ The reason for this may be two fold. Firstly, the increased bile acid concentration in gastric juice found in these patients will raise the $\mathrm{pH}$. Secondly, the mucosal abnormality, which is possibly caused by the bile reflux, leads to less secretion of acids.

In conclusion, we have found an association between probable premalignant gastric mucosal changes and intragastric bile acid concentration in a group of patients who have undergone vagotomy and gastrojejunostomy. This suggests the possibility of an aetiological role for bile in the pathogenesis of premalignant changes in the stomach after operation.

\section{References}

' Krause U. Late prognosis after partial gastrectomy for ulcer. Acta Chir Scand 1958;114:341-54.

${ }^{2}$ Stalsberg H, Taksdal S. Stomach cancer following gastric surgery for benign conditions. Lancet 1971;ii:1175-7.

${ }^{3}$ Schrumpf E, Serck-Hanssen A, Stadaas J, Aune S, Myren J, Osnes M. Mucosal changes in the gastric stump 20-25 years after partial gastrectomy. Lancet 1977;i:467-9.

4 Papachristou DN, Agnanti N, Fortner JG. Gastric carcinoma after treatment of ulcer. Am J Surg 1980;139:193-6.

${ }^{5}$ Farrands PA, Blake JRS, Ansell ID, Cotton RE, Hardcastle JD. Endoscopic review of patients who have had gastric surgery. Br Med J 1983;286:755-8.

- Watt PCH, Sloan JM, Kennedy TL. Changes in gastric mucosa after vagotomy and gastrojejunostomy for duodenal ulcer. $\mathrm{Br}$ Med J 1983;287:1407-10.

${ }^{7}$ Domellof L, Eriksson S, Janunger K-G. Late precancerous changes and carcinoma of the gastric stump after Billroth I resection. Am J Surg 1976;132:26-31.

${ }^{8}$ Domellof L, Eriksson S, Janunger K-G. Carcinoma and possible precancerous changes of the gastric stump after Billroth II resection. Gastroenterology 1977;73:462-8.

' Ruddell WSJ, Bone ES, Hill MJ, Blendin LM, Walters CL. Gas- 
tric juice nitrite, a risk factor for cancer in the hypochlorhydric stomach. Lancet 1976;ii: 1037-9.

${ }^{10}$ Reed PI, Haines K, Smith PLR, House FR, Walters CL. Gastric juice $\mathrm{N}$-nitrosoamines in health and gastroduodenal disease. Lancet 1981;ii:550-2.

" Domellof L. Gastric carcinoma promoted by alkaline reflux gastritis - with special reference to bile and other surfactants as promoters of postoperative gastric cancer. Medical Hypothesis 1979;5:463-76.

1 a Fausa O, Skalhegg BA. Quantitative determination of bile acids and their conjugates using thin layer chromatography and a purified $3 \alpha$ hydroxysteroid dehydrogenase. Scand J Gastroenterol 1974;9:249-54.

${ }^{12}$ McLean Ross AH, Smith MA, Anderson JR, Small WP. Late mortality after surgery for peptic ulcer. $N$ Engl $J$ Med 1982;307:519-22.

${ }^{13}$ Schmahl D, Habs M. Carcinogenicity of N-nitroso compounds. Oncology 1980;37:237-42.

${ }^{14}$ Milton-Thompson GJ, Ahmet Z, Lightfoot NF, et al. Intragastric acidity bacteria nitrite and $\mathrm{N}$-nitroso compounds before, during and after cimetidine treatment. Lancet 1982;i:1091-5.

${ }^{15}$ Reynolds KW, Johnson AG, Fox B. Is intestinal metaplasia of the gastric mucosa a pre-malignant lesion? Clin Oncol 1975; 1:101-9.

${ }^{16}$ Morson BC, Sobin LH, Grundmann E, Johansen A, Nagayo T, Serck-Hanssen A. Precancerous conditions and epithelial dysplasia of the stomach. J Clin Pathol 1980;33:711-21.

${ }^{17}$ Oehlert W, Keller P, Henke M, Strauch M. Gastric mucosal dysplasia: what is its clinical significance. Front Gastrointest Res 1979;4:173-82.

${ }^{18}$ Whitehead R. Mucosal biopsy of the gastrointestinal tract. 2nd ed. New York: WB Saunders Co, 1979:16-7.

${ }^{19}$ Mosimann F, Burri B, Diserens H, Fontolliet C, Loup P, Mosimann R. Enterogastric reflux: experimental and clinical study. Scand J Gastroenterol 1981;16 (suppl 67):149-52.

${ }^{20}$ Mosimann R, Loup P, Fontolliet C, Mosimann F. Post operative reflux gastritis. Scand J Gastroent 1981;16 (suppl 67):237-9.
${ }^{21}$ Heading RL. Duodenogastric reflux. Gut 1983;24:507-9.

${ }^{22}$ Hoare AM, Keighley MRB, Staricey B, Alexander-Williams J. Measurement of bile acids in fasting gastric aspirates: an objective test for bile reflux after gastric surgery. Gut 1978;19:166-9.

${ }^{23}$ Ritchie WP. Alkaline reflux gastritis. An objective assessment of its diagnosis and treatment. Ann Surg 1980;192:288-98.

${ }^{24}$ Thomas WEG, Cooper MJ, Mortensen NJ, Burton P, Davies ER. Positive correlation between duodenogastric reflux and gastric dysplasia. Gut 1983;24:A476.

${ }^{25}$ Domellof L, Reddy BS, Weisburger JH. Microflora and deconjugation of bile acids in alkaline reflux after partial gastrectomy. Am J Surg 1980;140:291-5.

${ }^{26}$ Reddy BS, Narasawa J, Weisburger JH. Promoting effect of sodium deoxycholate in colon adenocarcinoma in germ free rats. J Nat Cancer Inst 1976;56:441-2.

${ }^{27}$ Hill MJ, Drasar BS, Aries V, Crowther JS, Hawksworth G, Williams REO. Bacteria and the aetiology of cancer of the large bowel. Lancet 1971;i:95-100.

${ }^{28}$ Muscroft TJ, Deane SA, Young D, Burdon DW, Keighley MRB. The microflora of the post-operative stomach. Br J Surg 1981;68:560-4.

${ }^{29}$ Dewar P, King R, Johnston D. Bile acid and lysolecithin concentrations in the stomach in patients with duodenal ulcer before operation and after treatment by highly selective vagotomy, partial gastrectomy and truncal vagotomy and drainage. Gut 1982;23:569-77.

${ }^{30}$ Watt PCH, Sloan JM, Donaldson JD, Patterson CC, Kennedy TL. Relationship between histology and gastric juice $\mathrm{pH}$ and nitrite in the stomach after operation for duodenal ulcer. Gut 1984;25:246-52.

Requests for reprints to: Dr PCH Watt, Department of Pathology, Royal Victoria Hospital, Belfast, BT12 6BA, N Ireland. 